\title{
Untangling Malnutrition, Physical Dysfunction, Sarcopenia, Frailty and Cachexia in Ageing
}

\author{
Carla M. Prado, Jack J. Bell, and M. Cristina Gonzalez
}

\begin{abstract}
Malnutrition, sarcopenia, frailty and cachexia are different conditions but have overlapping characteristics and consequences for older adults. These conditions are especially prevalent in hospitalised patients affecting almost two thirds of older adults. They can often be hidden conditions; hence multidisciplinary awareness is needed for optimal identification and management. This chapter provides an overview of the definitions of each of these syndromes, its detrimental impact on health outcomes of older adults and tips for clinical practice implementation.
\end{abstract}

\section{Keywords}

Definitions $\cdot$ Muscle mass $\cdot$ Malnutrition $\cdot$ Sarcopenia $\cdot$ Frailty $\cdot$ Physical function Cachexia

C. M. Prado ( $\triangle)$

Nutrition, Food and Health, University of Alberta, Edmonton, AB, Canada

Faculty of Agricultural, Life and Environmental Science - Agricultural, Food \& Nutri Science Department, University of Alberta, Edmonton, AB, Canada

e-mail: carla.prado@ualberta.ca

J. J. Bell

Allied Health, The Prince Charles Hospital, Chermside, Queensland, Australia

School of Human Movement and Nutrition Sciences, The University of Queensland, St Lucia, QLD, Australia

e-mail: jack.bell@health.qld.gov.au

M. C. Gonzalez

Post-graduate Program in Health and Behavior, Catholic University of Pelotas,

Pelotas, RS, Brazil

Ó. G. Geirsdóttir, J. J. Bell (eds.), Interdisciplinary Nutritional Management and Care for Older Adults, Perspectives in Nursing Management and Care for Older Adults, https://doi.org/10.1007/978-3-030-63892-4_8 


\section{Learning Outcomes}

By the end of this chapter, you will be able to:

- Recognise the commonalities and differences among malnutrition, physical dysfunction, sarcopenia, frailty and cachexia.

- Report prevalence and consequences of these conditions in older adults.

- Justify nutritional interventions and tips for clinical practice implementation.

\subsection{Preface}

A 65-year-old male presenting with excess body weight (body mass index $\left.(B M I)=31 \mathrm{~kg} / \mathrm{m}^{2}\right)$ and reporting no concerns is at your clinic today for annual check-up. During the consultation, the patient casually mentions he often needs help with opening jars noting he is not as strong as he used to be'. Physical examination, blood pressure and laboratory results are normal.

This patient is likely suffering from sarcopenia, a condition often observed with ageing, and that associates with functional decline, among other outcomes. Low muscle mass is a defining feature of sarcopenia, also associated with other conditions discussed in this chapter: malnutrition, frailty and cachexia (Table 8.1). In fact, these syndromes may overlap, and almost two thirds of older medical inpatients would show at least one of these conditions [1].

\subsection{Definitions, Diagnosis, Prevalence and Relevance}

\subsubsection{Malnutrition}

According to the World Health Organization (WHO), malnutrition is a condition associated with deficiencies, excesses or imbalances in a person's intake of energy and/or nutrients. It includes undernutrition, micronutrient-related malnutrition, excess body weight and diet-related communicable disease [2]. Although different

Table 8.1 Malnutrition, sarcopenia, frailty and cachexia: differences and similarities

\begin{tabular}{|l|l|l|l|l|}
\hline Weight loss & Malnutrition & Sarcopenia & Frailty & Cachexia \\
\hline Low body mass index (BMI) & X & $?$ & X & X \\
\hline Muscle loss/weakness & X & $?$ & X & X \\
\hline Fat loss & X & X & X & X \\
\hline Inflammation & $?$ & $?$ & $?$ & $?$ \\
\hline Loss of appetite/nutrition impact symptoms & X & $?$ & $?$ & X \\
\hline Low food intake & X & - & $?$ & X \\
\hline
\end{tabular}

$\mathrm{X}=$ yes/usually present, $?=$ not necessarily present 
criteria have been proposed for the diagnosis of undernutrition or protein-energy malnutrition (malnutrition), a global consensus was recently commissioned by major scientific societies, launching the Global Leadership Initiative on Malnutrition (GLIM) empirical diagnostic consensus [3]. According to the GLIM criteria, the diagnosis of malnutrition is divided into phenotypic and etiologic criteria, with two stages of severity (moderate and severe) (Table 8.2). These, and other wellrecognised malnutrition diagnostic tools, ensure the diagnosis of malnutrition is not reliant on single-point measures such as BMI, albumin, identification of less than expected fat mass and/or reduced muscle mass or function alone. Suitable diagnostic tools should consider evidence of weight loss, low BMI or reduced muscle mass in combination with either inadequate intake or uptake of protein and/or energy sources or increased requirements for protein and energy. For example, an individual may have experienced weight loss and muscle depletion as a result of strokerelated inactivity. However, unless protein or energy intake is deficient or the subject has a co-morbid condition increasing metabolic requirements, these would not be diagnosed as malnutrition. Conversely, a high BMI alone does not preclude malnutrition, for example, in a person with obesity with sustained inadequate protein intake and consequent muscle loss [17].

Older adults are at risk for malnutrition. Malnutrition in this population may be associated with physiological, disease- or age-related changes, socio-economic or cultural factors, in addition to misinformation or misconceptions which can impact accessibility to food or adequacy of protein/energy intake [18]. These are detailed in Chaps. 3 and 4.

Malnutrition may go unrecognised in older adults due to a broad variety of factors, including failure to screen for malnutrition; poor screening tool sensitivity; reliance on inappropriate diagnostic measures, for example, albumin; and the misconception that malnutrition is only present in patients who are thin. With increasing prevalence of obesity globally, observing a diagnosis of overweight or obese malnutrition (DOOM) in older hospitalised patients is not uncommon and increases the likelihood of hospital-acquired complications, reduced mobility and 12-month mortality [17, 19]. A misdirected healthy selfimage, association of unintentional weight loss as a perceived positive benefit or a denial of reducing intake or unintentional weight loss to maintain a positive effect leads many malnourished patients to report their nutrition status as good to excellent $[18,20]$.

As mentioned in previous chapters, a 2016 systematic review of 54 studies using validated tools to screen for malnutrition in community-living adults concluded that up to $83 \%$ of adults age 65 and older are at risk for malnutrition [21]. A multinational effort to describe the prevalence of malnutrition [22] in 12 countries has reported this condition to be present in approximately $50 \%$ of those in rehabilitation, $39 \%$ in those hospitalised, $14 \%$ in residential care and $6 \%$ in community-living older adults. Malnutrition in older adults leads to detrimental impacts on health, cognitive and physical functioning and quality of life [23]. It has been associated with increased healthcare costs and short time survival [18]. 


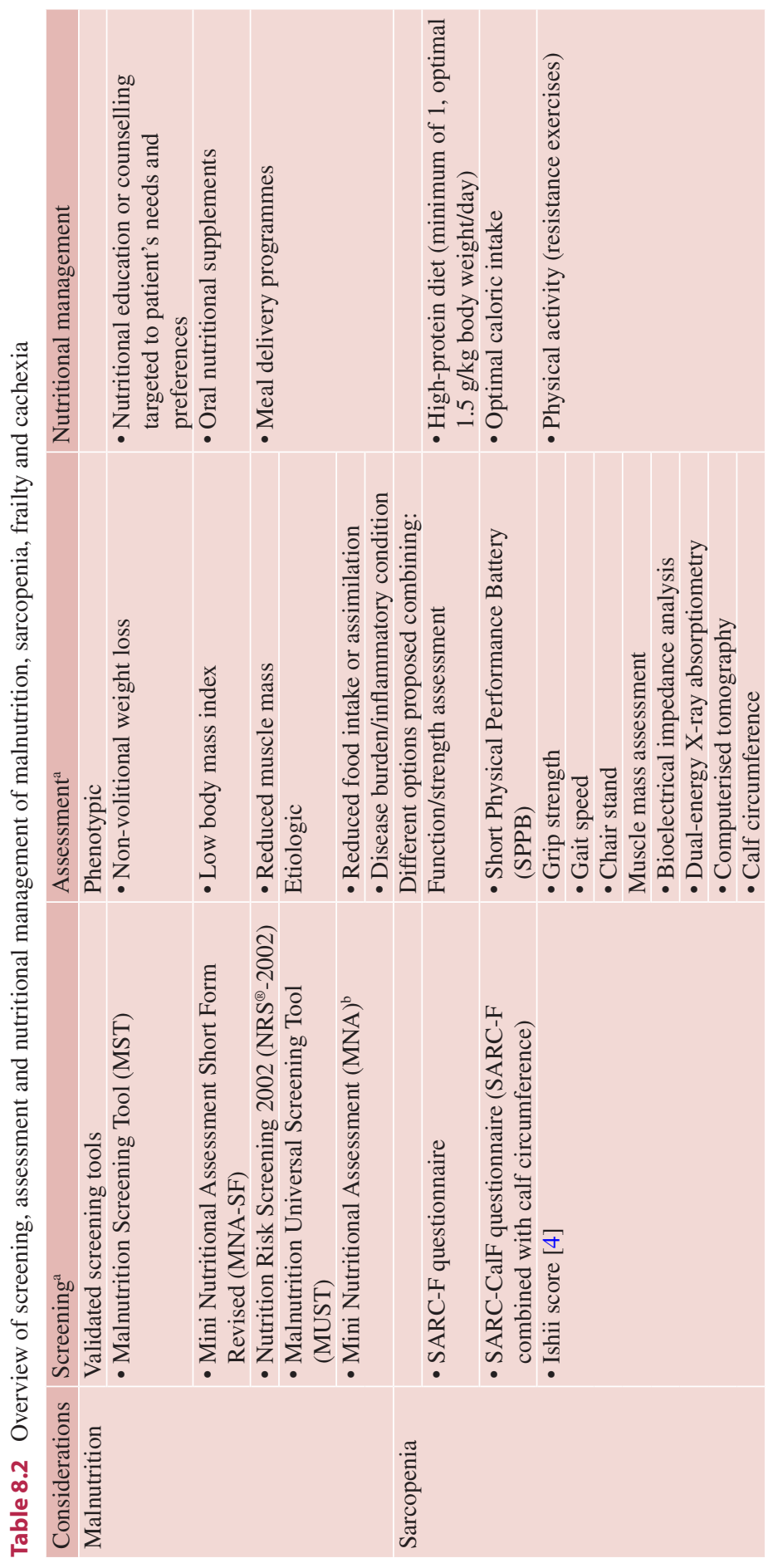




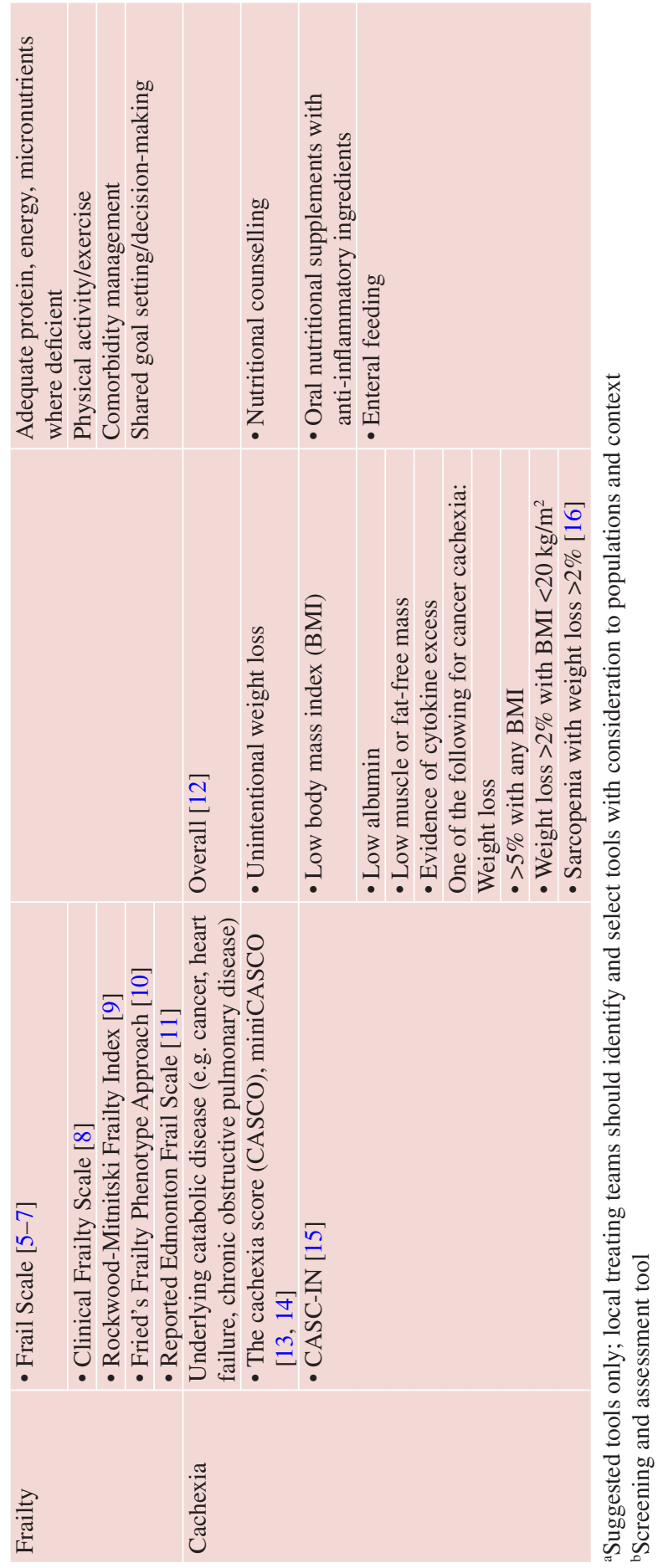




\subsubsection{Low Muscle Mass, Physical Dysfunction and Sarcopenia}

The loss of muscle mass and strength in ageing is studied in the context of sarcopenia. Although muscle mass and strength decline progressively after the age of 40, this loss is accelerated with advancing age (65 and older), becoming even more pronounced in individuals aged 85 and older. Estimates indicate that approximately $45 \%$ of older adults in the United States are affected by sarcopenia. Furthermore, sarcopenia has been reported to affect $30 \%$ of individuals over 60 years of age and more than $50 \%$ of people over 80 years [24]. A recent systematic review and metaanalysis of general population studies including 58,404 individuals found that $10 \%$ of men (95\% CI 8-12\%) and $10 \%$ of women (95\% CI 8-13\%) had sarcopenia [25]. Notably, prevalence rates are widely variable depending on the diagnostic criteria used.

Similar to malnutrition, there is no gold standard for screening or diagnosing sarcopenia. A well-recognised screening tool for sarcopenia is the SARC-F questionnaire [26] which measures strength, assistance needed in walking across a room, rising from chair/bed difficulty, climbing stars and falls. The addition of calf circumference to this questionnaire has been found to improve the sensitivity of SARC-F [27].

Several approaches are available for the diagnosis of sarcopenia such as the European Working Group on Sarcopenia in Older People (EWGSOP-2) [28], the Foundation for the National Institutes of Health (FNIH) initiative [29] and the Asian Working Group for Sarcopenia (AWGS) [30]. Notably, cut-off points for sarcopenia diagnosis should be race- and most often sex-specific. For a description of approaches and cut-offs, we refer the reader to Landi et al. [31], which includes the most commonly used definitions, with the exception of the EWGSOP which has been recently updated. The EWGSOP-2 now defines low muscle strength as a key criterion, followed by low muscle mass to confirm the sarcopenia diagnosis and gait speed to diagnose the severity of the condition [28].

The use of mass versus function conundrum is an ongoing source of debate related to sarcopenia diagnosis. Sarcopenia of ageing is considered primary sarcopenia, but in the context of a chronic disease (i.e. independent of ageing), sarcopenia is considered secondary sarcopenia as observed in the context of cancer, pulmonary diseases, heart failure and kidney disease, among others [32]. Patients may have both but the difference is that the diagnosis of secondary sarcopenia is widely pursued using measures of muscle mass alone. Therefore, secondary sarcopenia can be identified by low muscle mass.

Body composition techniques commonly used to diagnose low muscle mass include dual-energy X-ray absorptiometry (DXA), bioelectrical impedance analysis (BIA), computerised tomography and magnetic resonance imaging [28], although the latter is extremely limited and solely used in research settings. We refer the reader to a more in-depth discussion of the pros and cons of each body composition assessment technique [33, 34] and available cut-offs. Of increasing interest is the use of calf circumference, which correlates well with muscle mass, but has been primarily studied in older adults. Although calf circumference is only a proxy of 
muscle mass, it is the most commonly used tool for muscle mass assessment in clinical practice [35].

Sarcopenia in ageing occurs at any body weight and BMI; in individuals with obesity, it is termed sarcopenic obesity, a condition related to worse health outcomes than either in isolation. The prevalence of sarcopenic obesity is on the rise due to the ageing of the population and the obesity epidemic [36]. Diagnostic criteria are as variable for this condition as is the diagnosis of sarcopenia and obesity in isolation, although a consensus proposal is in the works by an international expert panel [37].

Criteria included in screening and diagnostic tools for sarcopenia (versus malnutrition) are shown in Table 8.2. Sarcopenia is a debilitating syndrome associated with disability, physical impairments, falls and fractures, decreased quality of life, hospitalisations and death [28]. Its related direct healthcare costs in the Unites States are estimated to be greater than $\$ 18$ billion per year, with a total estimated cost of hospitalisation of $\$ 40$ billion per year [38]. A $10 \%$ reduction in the prevalence of sarcopenia could translate to $\$ 1.1$ billion cost savings [39]. Due to the importance of sarcopenia, the WHO recently released the International Classification of Diseases code for sarcopenia (ICD-10 under the code M62.84; sarcopenia related to age), a major advancement for clinical practice and research.

\subsubsection{Frailty}

Definitions of frailty syndrome generally consider a combination of age- or diseaserelated physiological decline $[40,41]$ across multiple physiological systems, weakness or fatigue, reduced likelihood of positive outcome from healthcare interventions and/or increased susceptibility to adverse health outcomes.

There is no gold standard for the diagnosis of frailty, with a perhaps an overwhelming selection of screening or diagnostic options to consider [40]. Tools are commonly aligned to either a 'phenotypic' or 'deficit accumulation' framework. The former of these targets observable characteristics, for example, reduced activity, function, strength or energy levels, whilst the latter focusses on cumulative totals of co-morbidities or conditions. Some suggested frailty screening and assessment tools recommended by the Agency for Clinical Innovation are listed in Table 8.2; however which tools to apply should be considerate of contextual factors. A detailed overview of commonly used frailty instruments is provided elsewhere $[40,41]$. As such local treating teams are encouraged to carefully consider which tool is most likely to assist appropriate frailty identification and interventions.

The pathophysiology of frailty is complex, ranging from endocrine or immunological dysregulation, disease states and environmental, physiological or physical stressors, all of which may also contribute to sarcopenia, malnutrition or inflammatory processes. In fact, there is a close relationship between sarcopenia and physical frailty, and sarcopenia can be considered as the biological substrate for physical frailty [42]. 
A diagnosis of frailty is not inconsequential. Estimates of pre-frailty and frailty vary according to both screening and diagnostic tools applied, and genuine population differences, although many studies suggest prevalence between $10 \%$ and $40 \%$ of older populations [41, 43]. Regardless of the tools applied, frailty is routinely associated with functional decline, falls and fractures, hospital-acquired complications, hospitalisations and institutionalisation, reduced quality of life and increased mortality. The healthcare costs of frailty are increased at any level of care, including greater healthcare use and increased hospitalisation costs [43].

\subsubsection{Cachexia}

Cachexia is the most severe condition discussed in this chapter. It is associated with an underlying condition that leads to excessive catabolism [44] and has been studied in the context of cancer, congestive heart failure, chronic obstructive pulmonary disease and chronic kidney disease, among others [12, 45]. Together with precachexia, its prevalence across disease conditions has been estimated at 10-40\%, affecting more than 30 million people in the United States, based on a 2008 publication $[12,46]$.

Cachexia is a multimodal problem, where the presence of inflammatory cytokines, reduced food intake and metabolic dysfunction, including in energy metabolism, may contribute to its development and progression [47]. A multimodal intervention is now recognised ideal where nutrition, exercise and pharmacological interventions are included as part of optimal cancer care. A key element for successful treatment is the identification of cachexia in its earlier phase (precachexia), where inflammation is not so impactful, and nutritional counselling and protein supplements may prevent or decrease weight loss.

A defining feature of cachexia is muscle loss that occurs unrelated to changes in fat mass. Additionally, it has been associated with substantial inflammatory process, insulin resistance and an imbalance between protein synthesis and degradation, favouring the latter. Anorexia, weight loss and weakness are all associated with cachexia and of obvious unfavourable consequences to older adults. Patients with cancer cachexia have a poor prognosis; they present with poor physical function, poor quality of life and shorter survival.

Cachexia has been primarily studied in the context of cancer with an estimated prevalence at the European Union of 30\% [48]. The most commonly used criteria for cancer cachexia is shown in Table 8.2 and is based on an international consensus group [16]. Sarcopenia in the context of cachexia is defined as secondary sarcopenia, and hence, only measures of muscle mass have been used in the great majority of publications assessing sarcopenia in cachexia. This is also endorsed by the consensus group [16]. Definitions of sarcopenia of ageing (primary sarcopenia) that include measures of muscle strength/function have generally not been validated in the context of chronic diseases, including cancer. The diagnosis of low muscle mass (or sarcopenia) in cancer cachexia can be done using the body composition techniques or surrogate assessments described in Sect. 8.2.2. Based on the consensus 
group [16], physical examination including anthropometry can be used to estimate or evaluate muscle mass status, although they are not as accurate as body composition assessment techniques. Bioelectrical impedance analysis and computerised tomography scans are among the most popular bedside tools for the estimation and measurement (respectively) of body composition in cancer cachexia publications.

\subsection{Nutritional Treatment and Management Approaches}

Nutrition is a powerful therapy. Every other therapeutic approach is likely to fail if essential nutrients are not provided for optimal energy intake and muscle anabolism. An overview of nutritional management approaches for the conditions discussed in this chapter is shown in Table 8.2. Additional details on nutrition support are provided in Chap. 5.

In the context of malnutrition, common dietary approaches include multidisciplinary nutritional interventions, dietary intensive treatment, medical treatment and meal delivery service (e.g. Meals on Wheels) [49]. Individuals with poor nutrition knowledge are at greater risk to develop malnutrition [50]; hence nutritional education has the potential to improve nutritional status although knowledge does not necessarily translate in healthy eating habits [51]. Helping with meal planning and use of social programmes during mealtimes may positively influence meal choices. Nutrient-rich, flavour-enhanced meals (with herbs and spices) and the addition of nutritional supplements are helpful strategies [52] (Chaps. 3-5).

In the context of sarcopenia, both the quantity and quality of nutrients are essential to sustain muscle mass as shown in Fig. 8.1. These nutrients are important to several conditions hereby discussed, and they have an important role to be explored

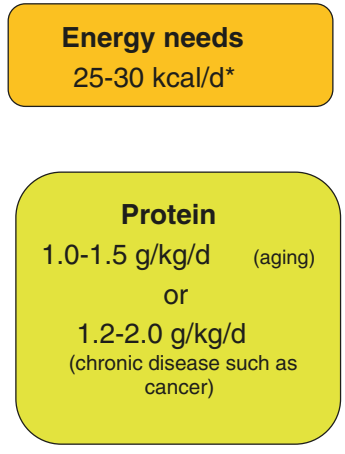

Fish oil/EPA

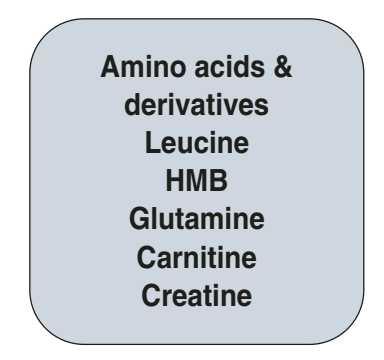

Vitamins/minerals

Fig. 8.1 Nutrients under consideration for the treatment of low muscle mass. HMB beta-hydroxy beta-methylbutyrate, EPA eicopentaenoic acid. (Adapted from Prado et al. J Cachexia Sarcopenia Muscle. 2020; 11: 366-380 [53] and Prado et al. Ann Med. 2018;50:675-693) 
in the context of prevention and treatment of muscle wasting. However, with the exception of targeted energy and protein needs, there is insufficient evidence to support additional supplementation of nutrients shown in Fig. 8.1. Furthermore, vitamins and minerals should be provided at Dietary Reference Intake levels. More research is needed to explore the impact of these nutrients alone or as part of a multimodal approach to maximise patient's anabolic potential $[32,53,54]$.

With respect to frailty, evidence supports ensuring adequate protein, energy and micronutrient intakes. Additional work is required to confirm whether multimodal approaches, combining nutrition care with physical activity $[55,56]$, comorbidity management and provision of advice on health behaviour improvements prevent or ameliorate frailty in the reversible phases of the condition [41, 43]. The available limited research on the effectiveness of system-level interventions is inconclusive (Table 8.1) [41, 43]. However, in the absence of adequate supporting evidence, we would suggest teams consider multi-model, interdisciplinary interventions at the individual and system levels across the continuum of care (Chaps. 1, 3-6, and 13). Treating teams should also ensure that chosen interventions are aligned with treatment intent, goal setting and shared decision-making processes (Chap. 21).

In the context of cachexia, nutrition therapy depends on individual patient's needs. Recently published guidelines for the management of cancer cachexia (which can be translated to other clinical settings) [57] acknowledge the importance of dietary counselling, fortified foods, oral nutritional supplements or enteral feds with adequate energy and protein (and potentially anti-inflammatory ingredients) as important nutritional strategies as outlined by Arends et al. [44]. In patients with less than 3-month life expectancy (i.e. refractory cachexia), nutrition is palliative, provided as needed to alleviate feelings of hunger and thirst [44]. Nutritional care should be adjusted according to patient's specific nutritional and metabolic requirements (Chap. 21).

In all the disease contexts, physical activity provides essential anabolic stimuli. Aerobic training may also help optimise fat mass. Pharmacological interventions have not been approved for the management of muscle wasting specifically but can be used to manage the underlying disease and unfavourable symptoms that can culminate in muscle loss. Therefore, this potentially offsets nutrition impact symptoms, optimising anabolism through increased food intake and anabolic potential.

\subsection{Key Levels to Implement Change}

An engaged multidisciplinary team can work collectively and collaboratively in the identification of malnutrition, physical dysfunction, sarcopenia, frailty or cachexia. Nurses are the frontline staff with most patient contact who can also be responsible for screening patients for these conditions. Dietitians provide the specialised assessment and support of patient's nutritional status, and medical professionals can 
support the holistic approach and ensure integration of the care process with all members of the healthcare team. Documentation of the diagnosis and care plan is essential and all are responsible (Chaps. 3, 4, and 6).

Accurate assessment of these conditions should be at the core of management pathway for at risk patients [58]. Creating an institutional culture on the relevance of these conditions helps to redefine priorities and advance assessment/interventions and monitoring of a quality improvement programme [59] targeting malnutrition, physical dysfunction, sarcopenia, frailty or cachexia. Patient engagement is key to advancing care, and the use of animated videos, infographics and other patient resources can be instrumental to achieve that $[60,61]$. Selected examples can be watched using the following links provided below (see recommended viewing).

\subsection{Conclusion}

The syndromes hereby discussed are distinct yet interrelated. As such, their components should be considered as interlinked factors, one leading to another and on a potentially vicious cycle manner. A perfect diagnosis can be challenging for the healthcare team, especially as some of the conditions may be hidden, requiring an in-depth assessment of nutritional status. Optimisation of assessment and treatment can support timely and comprehensive care to older adults involving multimodal care across the continuum of care.

\section{References}

1. Gingrich A, Volkert D, Kiesswetter E, Thomanek M, Bach S, Sieber CC et al (2019) Prevalence and overlap of sarcopenia, frailty, cachexia and malnutrition in older medical inpatients. BMC Geriatr 19(1):120. https://doi.org/10.1186/s12877-019-1115-1

2. World Health Organization (2020) Malnutrition. https://www.who.int/news-room/factsheets/detail/malnutrition\#: :text=Malnutrition\%20refers $\% 20$ to $\% 20$ deficiencies $\% 2 \mathrm{C} \% 20$ excesses,low\%20weight\%2Dfor\%2Dage)\%3B. Accessed 28 Oct 2020

3. Cederholm T, Jensen GL, Correia M, Gonzalez MC, Fukushima R, Higashiguchi T et al (2019) GLIM criteria for the diagnosis of malnutrition - a consensus report from the global clinical nutrition community. Clin Nutr (Edin, Scot) 38(1):1-9. https://doi.org/10.1016/j. clnu.2018.08.002

4. Ishii S, Tanaka T, Shibasaki K, Ouchi Y, Kikutani T, Higashiguchi T et al (2014) Development of a simple screening test for sarcopenia in older adults. Geriatr Gerontol Int 14(Suppl 1):93-101. https://doi.org/10.1111/ggi.12197

5. Agency for Clinical Innovation NG. Frailty screening and assessment tools. https://www.aci. health.nsw.gov.au/resources/frailty-taskforce/reports/frailty-screening-and-assessment-tools

6. Victoria State Government hv. Identifying frailty. https://www2.health.vic.gov.au/ hospitals-and-health-services/patient-care/older-people/frailty/frailty-identifying

7. Woo J, Leung J, Morley JE (2012) Comparison of frailty indicators based on clinical phenotype and the multiple deficit approach in predicting mortality and physical limitation. J Am Geriatr Soc 60(8):1478-1486. https://doi.org/10.1111/j.1532-5415.2012.04074.x 
8. Rockwood K, Song X, MacKnight C, Bergman H, Hogan DB, McDowell I et al (2005) A global clinical measure of fitness and frailty in elderly people. Can Med Assoc J 173(5):489-495. https://doi.org/10.1503/cmaj.050051

9. Mitnitski AB, Song X, Rockwood K (2004) The estimation of relative fitness and frailty in community-dwelling older adults using self-report data. J Gerontol A Biol Sci Med Sci 59(6):M627-M632. https://doi.org/10.1093/gerona/59.6.m627

10. Fried LP, Tangen CM, Walston J, Newman AB, Hirsch C, Gottdiener J et al (2001) Frailty in older adults: evidence for a phenotype. J Gerontol A Biol Sci Med Sci 56(3):M146-M156. https://doi.org/10.1093/gerona/56.3.m146

11. Rolfson DB, Majumdar SR, Tsuyuki RT, Tahir A, Rockwood K (2006) Validity and reliability of the Edmonton Frail Scale. Age Ageing 35(5):526-529. https://doi.org/10.1093/ ageing/afl041

12. Morley JE, Thomas DR, Wilson M-MG (2006) Cachexia: pathophysiology and clinical relevance. Am J Clin Nutr 83(4):735-743. https://doi.org/10.1093/ajen/83.4.735

13. Argilés JM, Betancourt A, Guàrdia-Olmos J, Peró-Cebollero M, López-Soriano FJ, Madeddu C et al (2017) Validation of the CAchexia SCOre (CASCO). Staging cancer patients: the use of miniCASCO as a simplified tool. Front Physiol 8:92. https://doi.org/10.3389/fphys.2017.00092

14. Argilés JM, López-Soriano FJ, Toledo M, Betancourt A, Serpe R, Busquets S (2011) The cachexia score (CASCO): a new tool for staging cachectic cancer patients. J Cachexia Sarcopenia Muscle 2(2):87-93. https://doi.org/10.1007/s13539-011-0027-5

15. Argilés JM, López-Soriano FJ, Castillejo M, Moreno C, Madeddu C, Serpe R, Busquets S (2019) CASC-IN: a new tool to diagnose pre-cachexia in cancer patients. Ann Clin Oncol. https://doi.org/10.31487/j.ACO.2019.04.03

16. Fearon K, Strasser F, Anker SD, Bosaeus I, Bruera E, Fainsinger RL et al (2011) Definition and classification of cancer cachexia: an international consensus. Lancet Oncol 12(5):489-495. https://doi.org/10.1016/s1470-2045(10)70218-7

17. Bell JJ, Pulle RC, Lee HB, Ferrier R, Crouch A, Whitehouse SL (2021) Diagnosis of overweight or obese malnutrition spells DOOM for hip fracture patients: a prospective audit. Clin Nutr (Edin, Scot) 40:1905. https://doi.org/10.1016/j.clnu.2020.09.003

18. Mangels AR (2018) CE: malnutrition in older adults. Am J Nurs 118(3):34-41. https://doi. org/10.1097/01.NAJ.0000530915.26091.be

19. Ness SJ, Hickling DF, Bell JJ, Collins PF (2018) The pressures of obesity: the relationship between obesity, malnutrition and pressure injuries in hospital inpatients. Clin Nutr (Edin, Scot) 37(5):1569-1574. https://doi.org/10.1016/j.clnu.2017.08.014

20. Federal Interagency Forum on Aging-Related Statistics (2016) Older Americans 2016: key indicators of well-being. Federal Interagency Forum on Aging-Related Statistics, Washington, DC

21. Hamirudin AH, Charlton K, Walton K (2016) Outcomes related to nutrition screening in community living older adults: a systematic literature review. Arch Gerontol Geriatr 62:9-25. https://doi.org/10.1016/j.archger.2015.09.007

22. Kaiser MJ, Bauer JM, Rämsch C, Uter W, Guigoz Y, Cederholm T et al (2010) Frequency of malnutrition in older adults: a multinational perspective using the mini nutritional assessment. J Am Geriatr Soc 58(9):1734-1738. https://doi.org/10.1111/j.1532-5415.2010.03016.x

23. Corish CA, Bardon LA (2019) Malnutrition in older adults: screening and determinants. Proc Nutr Soc 78(3):372-379. https://doi.org/10.1017/s0029665118002628

24. Baumgartner RN, Koehler KM, Gallagher D, Romero L, Heymsfield SB, Ross RR et al (1998) Epidemiology of sarcopenia among the elderly in New Mexico. Am J Epidemiol 147(8):755-763. https://doi.org/10.1093/oxfordjournals.aje.a009520

25. Shafiee G, Keshtkar A, Soltani A, Ahadi Z, Larijani B, Heshmat R (2017) Prevalence of sarcopenia in the world: a systematic review and meta- analysis of general population studies. $\mathrm{J}$ Diab Metab Disord 16:21. https://doi.org/10.1186/s40200-017-0302-x

26. Malmstrom TK, Morley JE (2013) SARC-F: a simple questionnaire to rapidly diagnose sarcopenia. J Am Med Dir Assoc 14(8):531-532. https://doi.org/10.1016/j.jamda.2013.05.018 
27. Barbosa-Silva TG, Menezes AM, Bielemann RM, Malmstrom TK, Gonzalez MC (2016) Enhancing SARC-F: improving sarcopenia screening in the clinical practice. J Am Med Dir Assoc 17(12):1136-1141. https://doi.org/10.1016/j.jamda.2016.08.004

28. Cruz-Jentoft AJ, Bahat G, Bauer J, Boirie Y, Bruyère O, Cederholm T et al (2019) Sarcopenia: revised European consensus on definition and diagnosis. Age Ageing 48(1):16-31. https://doi. org/10.1093/ageing/afy 169

29. Studenski SA, Peters KW, Alley DE, Cawthon PM, McLean RR, Harris TB et al (2014) The FNIH sarcopenia project: rationale, study description, conference recommendations, and final estimates. J Gerontol A Biol Sci Med Sci 69(5):547-558. https://doi.org/10.1093/ gerona/glu010

30. Chen LK, Lee WJ, Peng LN, Liu LK, Arai H, Akishita M (2016) Recent advances in sarcopenia research in Asia: 2016 Update From the Asian Working Group for Sarcopenia. J Am Med Dir Assoc 17(8):767.e1-767.e7. https://doi.org/10.1016/j.jamda.2016.05.016

31. Landi F, Calvani R, Cesari M, Tosato M, Martone AM, Ortolani E et al (2018) Sarcopenia: an overview on current definitions, diagnosis and treatment. Curr Protein Pept Sci 19(7):633-638. https://doi.org/10.2174/1389203718666170607113459

32. Bauer J, Morley JE, Schols A, Ferrucci L, Cruz-Jentoft AJ, Dent E et al (2019) Sarcopenia: a time for action. An SCWD position paper. J Cachexia Sarcopenia Muscle 10(5):956-961. https://doi.org/10.1002/jcsm.12483

33. Prado CM, Heymsfield SB (2014) Lean tissue imaging: a new era for nutritional assessment and intervention. JPEN J Parenter Enteral Nutr 38(8):940-953. https://doi. org/10.1177/0148607114550189

34. Sheean P, Gonzalez MC, Prado CM, McKeever L, Hall AM, Braunschweig CA (2020) American Society for Parenteral and Enteral Nutrition Clinical Guidelines: the validity of body composition assessment in clinical populations. JPEN J Parenter Enteral Nutr 44(1):12-43. https://doi.org/10.1002/jpen.1669. Epub 2019 Jun 19. PMID: 31216070

35. Bruyère $\mathrm{O}$, Beaudart $\mathrm{C}$, Reginster J-Y, Buckinx F, Schoene D, Hirani V, Cooper C, Kanis JA, Rizzoli R, McCloskey E, Cederholm T, Cruz-Jentoft A, Freiberger E (2016) Assessment of muscle mass, muscle strength and physical performance in clinical practice. Eur Geriat Med 7(3):243-246. https://doi.org/10.1016/j.eurger.2015.12.009

36. Roubenoff R (2004) Sarcopenic obesity: the confluence of two epidemics. Obes Res 12(6):887-888. https://doi.org/10.1038/oby.2004.107

37. Donini LM, Busetto L, Bauer JM, Bischoff S, Boirie Y, Cederholm T et al (2020) Critical appraisal of definitions and diagnostic criteria for sarcopenic obesity based on a systematic review. Clin Nutr (Edin, Scot) 39(8):2368-2388. https://doi.org/10.1016/j. clnu.2019.11.024

38. Goates S, Du K, Arensberg MB, Gaillard T, Guralnik J, Pereira SL (2019) Economic impact of hospitalizations in US adults with sarcopenia. J Frailty Aging 8(2):93-99. https://doi. org/10.14283/jfa.2019.10

39. Janssen I, Shepard DS, Katzmarzyk PT, Roubenoff R (2004) The healthcare costs of sarcopenia in the United States. J Am Geriatr Soc 52(1):80-85. https://doi. org/10.1111/j.1532-5415.2004.52014.x

40. Buta BJ, Walston JD, Godino JG, Park M, Kalyani RR, Xue QL et al (2016) Frailty assessment instruments: systematic characterization of the uses and contexts of highly-cited instruments. Ageing Res Rev 26:53-61. https://doi.org/10.1016/j.arr.2015.12.003

41. Dent E, Martin FC, Bergman H, Woo J, Romero-Ortuno R, Walston JD (2019) Management of frailty: opportunities, challenges, and future directions. Lancet (Lond, Engl) 394(10206):1376-1386. https://doi.org/10.1016/s0140-6736(19)31785-4

42. Cruz-Jentoft AJ, Sayer AA (2019) Sarcopenia. Lancet (Lond, Engl) 393(10191):2636-2646. https://doi.org/10.1016/s0140-6736(19)31138-9 
43. Hoogendijk EO, Afilalo J, Ensrud KE, Kowal P, Onder G, Fried LP (2019) Frailty: implications for clinical practice and public health. Lancet (Lond, Engl) 394(10206):1365-1375. https://doi.org/10.1016/s0140-6736(19)31786-6

44. Arends J, Baracos V, Bertz H, Bozzetti F, Calder PC, Deutz NEP et al (2017) ESPEN expert group recommendations for action against cancer-related malnutrition. Clin Nutr (Edin, Scot) 36(5):1187-1196. https://doi.org/10.1016/j.clnu.2017.06.017

45. Yoshida T, Delafontaine $P$ (2015) Mechanisms of cachexia in chronic disease states. Am J Med Sci 350(4):250-256. https://doi.org/10.1097/maj.0000000000000511

46. Tan BH, Fearon KC (2008) Cachexia: prevalence and impact in medicine. Curr Opin Clin Nutr Metab Care 11(4):400-407. https://doi.org/10.1097/MCO.0b013e328300ecc1

47. Del Fabbro E (2019) Combination therapy in cachexia. Ann Palliat Med 8(1):59-66. https:// doi.org/10.21037/apm.2018.08.05

48. Anker MS, Holcomb R, Muscaritoli M, von Haehling S, Haverkamp W, Jatoi A et al (2019) Orphan disease status of cancer cachexia in the USA and in the European Union: a systematic review. J Cachexia Sarcopenia Muscle 10(1):22-34. https://doi.org/10.1002/jcsm.12402

49. Young C, Argáez C (2019) Interventions for malnutrition in older adults: a review of clinical effectiveness. CADTH rapid response report. Canadian Agency for Drugs and Technologies in Health (CADTH), Ottawa, ON, p 4

50. Smith ML, Bergeron CD, Lachenmayr S, Eagle LA, Simon JR (2020) A brief intervention for malnutrition among older adults: stepping up your nutrition. Int J Environ Res Public Health 17(10):3590. https://doi.org/10.3390/ijerph17103590

51. Turconi G, Rossi M, Roggi C, Maccarini L (2013) Nutritional status, dietary habits, nutritional knowledge and self-care assessment in a group of older adults attending community centres in Pavia, Northern Italy. J Hum Nutr Dietet 26(1):48-55. https://doi. org/10.1111/j.1365-277X.2012.01289.x

52. Mayo Clinic (2019) Senior health: how to prevent and detect malnutrition. https://www. mayoclinic.org/healthy-lifestyle/caregivers/in-depth/senior-health/art-20044699. Accessed 28 Oct 2020

53. Prado CM, Purcell SA, Laviano A (2020) Nutrition interventions to treat low muscle mass in cancer. J Cachexia Sarcopenia Muscle 11(2):366-380. https://doi.org/10.1002/jcsm.12525. Epub 2020 Jan 8. PMID: 31916411; PMCID: PMC7113510

54. Prado CM, Anker SD, Coats AJS, Laviano A, von Haehling S (2021) Nutrition in the spotlight in cachexia, sarcopenia and muscle: avoiding the wildfire. J Cachexia Sarcopenia Muscle 12(1):3-8. https://doi.org/10.1002/jcsm.12673. Epub 2020 Dec 31. PMID: 33382196; PMCID: PMC7890147

55. Hernández Morante JJ, Gómez Martínez C, Morillas-Ruiz JM (2019) Dietary factors associated with frailty in old adults: a review of nutritional interventions to prevent frailty development. Nutrients 11(1):102. https://doi.org/10.3390/nu11010102

56. Lorenzo-López L, Maseda A, de Labra C, Regueiro-Folgueira L, Rodríguez-Villamil JL, Millán-Calenti JC (2017) Nutritional determinants of frailty in older adults: a systematic review. BMC Geriatr 17(1):108. https://doi.org/10.1186/s12877-017-0496-2

57. Roeland EJ, Bohlke K, Baracos VE, Bruera E, Del Fabbro E, Dixon S et al (2020) Management of cancer cachexia: ASCO guideline. J Clin Oncol Off J Am Soc Clin Oncol 38(21):2438-2453. https://doi.org/10.1200/jco.20.00611

58. Deutz NEP, Ashurst I, Ballesteros MD, Bear DE, Cruz-Jentoft AJ, Genton L et al (2019) The underappreciated role of low muscle mass in the management of malnutrition. J Am Med Dir Assoc 20(1):22-27. https://doi.org/10.1016/j.jamda.2018.11.021

59. Tappenden KA, Quatrara B, Parkhurst ML, Malone AM, Fanjiang G, Ziegler TR (2013) Critical role of nutrition in improving quality of care: an interdisciplinary call to action to address adult hospital malnutrition. JPEN J Parenter Enteral Nutr 37(4):482-497. https://doi. org/10.1177/0148607113484066

60. George S, Moran E, Duran N, Jenders RA (2013) Using animation as an information tool to advance health research literacy among minority participants. AMIA Annu Symp Proc 2013:475-484 
61. Keselman A, Logan R, Smith CA, Leroy G, Zeng-Treitler Q (2008) Developing informatics tools and strategies for consumer-centered health communication. J Am Med Inform Assoc 15(4):473-483. https://doi.org/10.1197/jamia.M2744

\section{Recommended Videos}

Alliance for Aging Research (2020) Sarcopenia: taking charge of your muscle health as you age. https://www.youtube.com/watch?v=CAC2g03_-2Y\&t=81s. Accessed 8 Apr 2021

Prado C (2020) The importance of nutrition to prevent and treat low muscle mass. https://www. youtube.com/watch?v=pDSX_jaDCDM. Accessed 8 Apr 2021

Open Access This chapter is licensed under the terms of the Creative Commons Attribution 4.0 International License (http://creativecommons.org/licenses/by/4.0/), which permits use, sharing, adaptation, distribution and reproduction in any medium or format, as long as you give appropriate credit to the original author(s) and the source, provide a link to the Creative Commons license and indicate if changes were made.

The images or other third party material in this chapter are included in the chapter's Creative Commons license, unless indicated otherwise in a credit line to the material. If material is not included in the chapter's Creative Commons license and your intended use is not permitted by statutory regulation or exceeds the permitted use, you will need to obtain permission directly from the copyright holder.

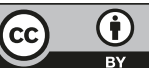

